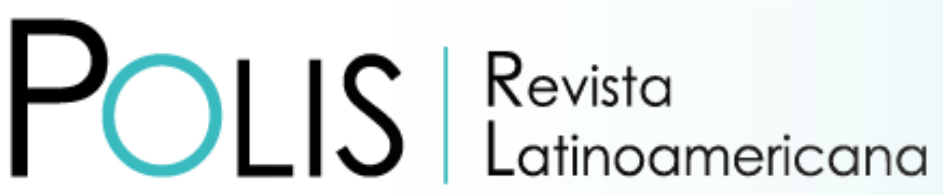

V20 | N59 | 2021

DOI: $10.32735 /$ S0718-6568/2021-N59-1594

\title{
Desborde y desazón versus flexibilidad y concentración: Teletrabajo académico y género en tiempos de pandemia
}

\author{
Rosario Undurraga \\ Universidad Finis Terrae, Santiago, Chile \\ Email: mrundurraga@uft.cl \\ Elisabeth Simbürger \\ Universidad de Valparaíso, Valparaíso, Chile \\ Email: elisabeth.simbuerger@uv.cl \\ Claudia Mora \\ Universidad Mayor, Santiago, Chile \\ Email: claudia.mora@umayor.cl
}

Recibido: 20.11 .2020

Aceptado: 18.03.2021

\begin{abstract}
Resumen: La relación entre vida personal y trabajo se ha hecho evidente durante la pandemia del COVID-19: trabajo remunerado, trabajo doméstico, cuidados, vida personal y familiar coexisten en el mismo espacio y tiempo. El trabajo inundó los espacios del hogar y reubicó al teletrabajo en el centro del mundo de lo doméstico. Esta investigación cualitativa analiza la experiencia de teletrabajo bajo pandemia para académicas en Chile. A través de entrevistas foto-provocadas a una muestra de 15 académicas de universidades del norte, centro y sur de Chile, el artículo aborda la neutralidad institucional universitaria respecto al género como una estructura que profundiza desigualdades y excluye a académicas con responsabilidades de cuidado.

Los resultados muestran una intensificación y extensión de la jornada online, una sobrecarga de trabajo reproductivo, simultaneidad de tareas, vulnerabilidad emocional y soledad, aunque para algunas académicas el trabajo a distancia también ha significado mayor concentración y flexibilidad laboral. Las variadas condiciones afectan profundamente la experiencia de teletrabajo, el bienestar y las posibilidades de generación de conocimiento y productividad científica. Ante la diversidad de realidades en relación al teletrabajo durante la crisis sanitaria, se plantea la necesidad urgente de políticas institucionales con perspectiva de género.
\end{abstract}

Palabras clave: Trabajo remoto; COVID-19; universidad; género; vida personal y laboral. 


\title{
Overflow and despair versus flexibility and concentration: Academic teleworking and gender in times of pandemic
}

\begin{abstract}
The relationship between work and personal life has become evident during the COVID-19 pandemic: paid work, domestic work, care work, personal and family life coexist in the same space and time. Work flooded home spaces and telecommuting was relocated to the center of the domestic realm. This qualitative research analyzes the experience of female academics working remotely during the pandemic in Chile. Through photo-elucidated interviews with a sample of 15 academics from universities from the north, center and south of Chile, the article addresses university-institutionalized gender neutrality as a structure that deepens inequalities and excludes academic women with caretaking responsibilities. The results show an intensification and extension of the online workday, an overload of reproductive work, simultaneity of tasks, emotional vulnerability and isolation. Yet, for some academics, remote work has also meant greater concentration and work flexibility. The various conditions profoundly affect the remote work experience and personal well-being of female academics, as well as their possibilities for knowledge production and scientific productivity. Given the diversity of realities for remote work during the health crisis, university policies on remote work with a gender perspective are urgently required.
\end{abstract}

Keywords: Remote work; COVID-19; university; gender work-life balance.

\section{Excesso e desespero versus flexibilidade e concentração: Teletrabalho acadêmico e gênero em tempos de pandemia}

Resumo: A relação entre vida pessoal e trabalho tornou-se evidente durante a pandemia COVID-19: trabalho remunerado, trabalho doméstico, cuidado, vida pessoal e familiar coexistem no mesmo espaço e tempo. O trabalho inundou os espaços da casa e deslocou o teletrabalho para o centro do mundo doméstico.

Esta pesquisa qualitativa analisa a experiência do teletrabalho sob uma pandemia para acadêmicas no Chile. Por meio de entrevistas foto-provocadas com uma amostra de 15 acadêmicas de universidades do norte, centro e sul do Chile, o artigo aborda a neutralidade institucional universitária em relação ao gênero como uma estrutura que aprofunda as desigualdades e exclui acadêmicas com responsabilidades no trabalho de cuidado. Os resultados mostram uma intensificação e extensão da jornada de trabalho on line, uma sobrecarga de trabalho reprodutivo, tarefas simultâneas, vulnerabilidade emocional e solidão, embora para alguns acadêmicas o trabalho a distância também tenha significado maior concentração e flexibilidade. As diversas condições afetam profundamente a experiência do teletrabalho, o bem-estar e as possibilidades de geração de conhecimento e produtividade científica. Dada a diversidade de realidades em relação ao teletrabalho durante a crise sanitaria, é urgente a necessidade de políticas institucionais com perspectiva de gênero.

Palavras-chave: Trabalho remoto; COVID-19; faculdade; gênero; vida pessoal e profissional.

\section{Como citar este artículo:}

Undurraga, R., Simbürger, E. y Mora, C. (2021). Desborde y desazón versus flexibilidad y concentración: Teletrabajo académico y género en tiempos de pandemia. Polis Revista Latinoamericana, 20 (59), 12-38. doi: http://dx.doi.org/10.32735/S0718-6568/2021-N59-1594 


\section{Introducción}

La relación entre vida personal/familiar y trabajo remunerado se ha tornado evidente durante la pandemia del SARS-CoV-2: trabajo remunerado, trabajo de cuidado, trabajo doméstico y vida personal/familiar han compartido espacio, tiempo y recursos en el transcurso de meses de confinamiento forzado por la crisis sanitaria. En el abrupto tránsito hacia el trabajo remoto, las tensiones entre estos distintos ámbitos han definido las experiencias de vida de un gran número de profesionales, planteando serios desafíos laborales para quienes tienen responsabilidades de cuidado de dependientes. En Chile, el confinamiento comenzó al inicio del año académico (marzo 2020) y perduró casi todo el año, teniendo una de las cuarentenas más largas del mundo.

El efecto de la pandemia del COVID-19 no ha estado limitado al trabajo remoto, pero sí ha recaído especialmente en las mujeres trabajadoras. De acuerdo al Boletín de Empleo de junio 2020 del Instituto Nacional de Estadísticas de Chile, la tasa de participación laboral femenina bajó a niveles no vistos desde hace una década (a un magro 42,9\%, en mayo de 2020), mientras que el trabajo informal de las mujeres mostró una disminución de más del $33 \%$, por el impacto de la pandemia en el comercio y servicio de alojamiento y comidas, actividades feminizadas en el país (Instituto Nacional de Estadísticas [INE], 2020a). En el caso de las universidades, las aulas presenciales se clausuraron tempranamente en la pandemia y se implementaron clases online y teletrabajo académico, lo que demandó labores remotas de docencia, investigación, escritura de manuscritos, coordinación de equipos, atención de estudiantes, participación en webinars, entre otras múltiples tareas a distancia.

En este artículo nos enfocamos en un grupo particular de trabajadores de alta calificación para explorar las experiencias laborales de académicas, quienes enfrentaron repentinamente el teletrabajo en confinamiento sanitario, en paralelo con el cierre presencial de colegios y jardines infantiles, y la suspensión de redes de apoyo al cuidado y el trabajo doméstico. Nos preguntamos: ¿̇cómo ha sido la experiencia de académicas en Chile que realizan teletrabajo académico y clases online desde el hogar, en conjunto con otras demandas y responsabilidades, durante esta pandemia? ¿̇De qué manera los contextos institucionales, personales y condiciones de vida de las académicas han definido su relación con el trabajo y la universidad, perfilando trayectorias diferenciadas en relación a sus pares masculinos, así como entre académicas? A través de entrevistas foto-provocadas, este artículo analiza la exacerbación de las desigualdades de género en el teletrabajo académico en pandemia, evidenciando desventajas laborales para académicas que desarrollan labores de cuidado, así como desventajas emocionales para aquellas en hogares unipersonales. Lo anterior nos lleva a reflexionar sobre las políticas institucionales que permitirían re-imaginar la diversidad en la universidad para sentar bases sólidas para la producción de conocimiento. A partir de esta mirada, nos enfocaremos en la diversidad de experiencias en torno al teletrabajo académico durante la pandemia del COVID-19. 


\section{Género y pandemia}

La crisis sanitaria ha tenido consecuencias devastadoras para las condiciones de vida en Chile. En gran medida, ello se debe a que se han individualizado las responsabilidades de protección social (Araujo, 2017; Gárate, 2012; Undurraga, 2014), dejando al descubierto la fragilidad de las personas ante un sistema neoliberal. En tiempos de crisis, diversos estudios muestran que las vulnerabilidades de las mujeres se exacerban, aumentando significativamente su carga total de trabajo (Bradshaw, 2015; McLaren et al., 2020; Mondal, 2014; Moreno y Shaw, 2018), dado que las responsabilidades que emergen como resultado de las crisis -ya sea para hacerles frente o para sobrevivirlas- recaen en las mujeres. Esta sobrecarga se pliega sobre vulnerabilidades preexistentes, lo que profundiza la distribución inequitativa de tareas según género (MOVID-19, 2020; ONU Mujeres, 2020).

En Chile, las desigualdades de género se manifiestan con claridad en el mercado del trabajo (Han, 2012; Mora, 2013; Undurraga, 2019a; Undurraga, 2013). Aun cuando la participación laboral de las mujeres ha aumentado significativamente durante las últimas décadas, continúa siendo una de las más bajas de Latinoamérica y más de 20 puntos inferior a la de los hombres (INE, 2020a). La brecha salarial sigue desfavoreciendo a las mujeres, con salarios promedio más bajos que los de sus pares masculinos en las mismas categorías, brecha que se amplía a mayor nivel educacional (INE, 2020b); además, las mujeres permanecen en los rangos más bajos de las jerarquías ocupacionales y muestran una importante concentración en el trabajo informal (INE, 2020c). El mayor deterioro que ha experimentado la participación y condiciones laborales de las mujeres durante la crisis, reflejado en datos recientes, conlleva sustanciales efectos en sus trayectorias laborales, así como en la precariedad proyectada en su vejez (Undurraga y Becker, 2019; Undurraga, 2019b). Pero no es solo en lo laboral donde se han profundizado diferencias de género durante la pandemia del COVID-19. En Chile, la situación de las mujeres es crítica en distintos ámbitos: efectos nocivos en salud mental (Colegio Médico de Chile, 2020; Ministerio de la Mujer y la Equidad de Género [Minmujeryeg], 2020), aumento de violencia doméstica (López-Calva, 2020; Red Chilena contra la Violencia hacia las Mujeres, 2020), sobrecarga en las labores de cuidado (Micropolíticas del Cuidado, 2020), entre otros. En pandemia, las horas dedicadas a tareas reproductivas han aumentado significativamente para las mujeres (Bravo, Castillo y Hughes, 2020; Micropolíticas del Cuidado, 2020; ONU Mujeres, 2020), lo que ha agudizado las desigualdades en el trabajo remunerado en relación a sus pares hombres.

La aceleración de las transformaciones en el trabajo en tiempos de pandemia ha ido de la mano del uso de tecnologías de la información (TICS) y el trabajo a distancia. De acuerdo al INE, en el mes de junio, cerca del 37\% de los empleadores chilenos implementaron algún grado de teletrabajo a partir de la pandemia. No obstante, el porcentaje de trabajadores que lo realiza es solo un 25\% (INE, 2020d), es decir, el teletrabajo es una forma privilegiada de trabajar durante la pandemia, en comparación al universo de trabajadores en Chile que han continuado presencialmente a pesar de los riesgos, o han enfrentado suspensiones de contratos y despidos. 
Para los teletrabajadores, los desafíos radican en la implementación del trabajo remoto durante el confinamiento, marcado por el encierro, clausura presencial de colegios y la ausencia de apoyos externos de cuidado. En el caso de las académicas (profesoras universitarias), si los datos indican que tanto la distribución de labores en el hogar como la posición en el mercado laboral están definidas según género, y que se intensifican inequidades preexistentes en situaciones de crisis, ¿̇cómo será la situación de teletrabajo académico de las mujeres durante la pandemia del COVID-19 en Chile? .

\section{Teletrabajo académico y género en pandemia: nuevas brechas, viejos temas}

Las trayectorias académicas de las mujeres no distan demasiado de las experiencias de las trabajadoras en el mercado laboral chileno en general: el techo de cristal sigue vigente como un fenómeno global en las universidades, con la gran mayoría de cargos altos en manos de hombres. En Chile, solo hay cinco mujeres rectoras, lo que representa el $8,2 \%$ del total en el país (Véliz y Bernasconi, 2019). Si bien el 43,5\% del personal académico son mujeres (SIES, 2017, citado en Veliz y Bernasconi, 2019, p. 333) solo 3.000 de las 10.000 personas que poseen el título de Doctor en las universidades chilenas, son mujeres (SIES, 2017). Las mujeres consistentemente se adjudican menos fondos de investigación y esta sigue siendo liderada por hombres, mientras que la docencia continúa siendo una actividad altamente feminizada (Mandiola, Ríos y Varas, 2019; Ríos, Mandiola y Varas, 2017). Esto refleja una tendencia que no es exclusiva de Chile: las mujeres se desempeñan mayoritariamente en lo doméstico de la universidad, la docencia (Bartos y Ives, 2019), y menos en investigación, la mercancía prestigiosa en las universidades contemporáneas (Lutter y Schröder, 2019), que se vincula a incentivos económicos por publicaciones y es requisito de entrada para fondos de investigación (Sisto, 2020; Fardella, Sisto y Jiménez, 2017).

El avance más lento de las mujeres en la carrera académica se intensifica con el nacimiento y la crianza de los hijos y la nueva organización doméstica que esta requiere, mientras los pares hombres continúan su trayectoria profesional sin verse mayormente perjudicados por los cambios familiares (Ortiz, 2017). El antagonismo entre el trabajo reproductivo y el trabajo académico sigue siendo clave en las trayectorias académicas de gran parte de las mujeres (Martínez Labrín, 2012), quienes mantienen una segunda jornada laboral cuidando a sus hijos y dependientes, mientras asumen la carga principal de distintas tareas domésticas (Santos, 2015). Por tanto, las políticas de género son fundamentales en la equiparación del terreno en las universidades chilenas, sin embargo, su existencia es reducida: en el año 2016, solo 2 de 10 universidades estudiadas por Undurraga y Simbürger (2018) contaban con una Unidad de Género e Igualdad y con procedimientos legales en relación al género y la diversidad. En 2019, 10 de 58 instituciones de educación superior chilenas habían creado unidades de género. Esto significa que las académicas con responsabilidades de cuidado siguen resolviendo individualmente la conciliación del trabajo académico con la vida familiar y personal, transformándose en "académicas malabaristas", como Montes y Simbürger (2021) afirman en un estudio comparativo entre Chile y España. En modo etnográfico, varios 
escritos indican una intensificación de este fenómeno durante la pandemia (Simbürger, 2020a; Simbürger 2020b) y datos recientes dan cuenta de una baja en la productividad científica vinculada a la sobrecarga de trabajo para las mujeres (Fazackerley, 2020; Gabster et al., 2020; Minello, Martucci y Manzo, 2020).

Como sugiere la perspectiva interseccional (Mora, 2019), es necesario abordar la diversidad de experiencias y desafíos del teletrabajo entre las académicas, en la medida que esta se vincula con la realidad personal y familiar. Ante tal diversidad, las políticas universitarias han asumido una homogeneidad del cuerpo académico, o simplemente han carecido de respuesta institucional frente al teletrabajo. Si bien muchas universidades actuaron con rapidez frente a la pandemia en el ámbito de capacitaciones virtuales sobre tecnología y nuevas plataformas docentes, no han sido igualmente eficaces en la implementación de políticas en relación a la protección de las y los teletrabajadores y de medidas con perspectiva de género durante la pandemia del COVID-19. Las experiencias disímiles de académicas en teletrabajo están, de este modo, condicionadas por marcos normativos institucionales que no consideran esta diversidad y que, finalmente, profundiza las desigualdades de género en el trabajo académico, particularmente, para el grupo de académicas con responsabilidades de cuidado.

\section{Metodología}

El objetivo de este estudio es analizar la experiencia de académicas en Chile durante la pandemia del COVID-19, enfocándose en los beneficios y desafíos de realizar teletrabajo académico y clases online desde el hogar, en conjunto con otras demandas y responsabilidades. Esta investigación utiliza metodologías cualitativas pertinentes para lograr una aproximación a la realidad social desde la mirada de las participantes: académicas teletrabajando en el contexto de la pandemia COVID-19 en Chile.

\section{Metodo}

La técnica utilizada para la producción de datos es la entrevista semi-estructurada fotoprovocada en modalidad remota (Meo, 2010). La entrevista a través de foto elucidación toma un lugar particular dentro de la investigación social porque permite un acercamiento a un tema de estudio a partir de imágenes, conversando sobre las experiencias, procesos o memorias que provocan (Cappello, 2005). En los estudios visuales, se desarrolla el análisis de lo social a partir de la imagen (Prosser, 1998). Conversar a partir de una foto provoca asociaciones y diálogos mucho más profundos que la entrevista cualitativa tradicional, dado que lo visual activa otras capacidades de la mente que el nivel verbal (Harper, 2002). En una fotografía, se retratan experiencias que evocan palabras y discursos acerca de lo vivido, creando relatos de mayor profundidad y dando, además, agencia en el proceso de investigación a las entrevistadas (Meo y Dabenigno, 2011; Meo, 2010). En el caso del teletrabajo en pandemia, la entrevista foto-provocada parece ser particularmente apta 
como método, dado que la dimensión visual de la imagen permite una aproximación a lo multidimensional del teletrabajo y las simultaneidades de procesos que están (des) cubiertos, revelando estas facetas en el diálogo entre entrevistadora y entrevistada.

Previo a la entrevista, se solicitó a las participantes algunas fotos que retrataran su experiencia de teletrabajo académico durante la pandemia. Basándose en ellas, se llevó a cabo la conversación en torno a distintas dimensiones: (1) situación personal/familiar y antecedentes laborales; (2) teletrabajo y condiciones laborales; (2) teletrabajo académico: investigación, clases remotas, reuniones, políticas de la universidad; (3) relación con otras responsabilidades y labores (cuidado, domésticas, personales); (4) dimensión emocional y bienestar; (5) aprendizajes personales y laborales durante la pandemia. Las entrevistas se realizaron de forma remota debido a la crisis sanitaria, durante octubre y noviembre de 2020 a través de una plataforma virtual (meet y zoom). En promedio, duraron 1 hora y 4 minutos, siendo la más corta de 43 minutos y la más larga de 1 hora y 26 minutos. Las entrevistas fueron grabadas y transcritas textualmente (verbatim). El análisis de las entrevistas y el material fotográfico se inspiró en la teoría fundamentada (Grounded Theory) (Glaser y Holton, 2004; Glaser y Strauss, 1998). Para analizar el material textual y visual, se crearon categorías de análisis y relaciones a partir de los datos recolectados (Krause, 1995), destacando similitudes y diferencias entre participantes, así como elementos transversales. Tanto el material visual como textual fueron seleccionadas en base a las categorías de análisis emergentes.

\section{Muestra}

La muestra del estudio es intencionada. Está compuesta por 15 académicas entre 39 y 53 años, de diversas áreas (ciencias sociales, ciencias de la salud, ciencias biológicas y humanidades), diferentes jerarquías (titular, asociada, adjunta y asistente) y distintas universidades de Chile (públicas y privadas del norte, centro y sur del país). ' Las participantes tienen distintas situaciones personales/familiares: con y sin hijos, con y sin pareja, residentes en casas y departamentos con y sin espacio verde; 9 de la región Metropolitana y 6 de otras regiones del país. De la muestra, 11 participantes tienen hijos, cuyas edades fluctúan entre 1 y 21 años, y 4 no son madres (ver Tabla 1). Estos criterios abogan por una cierta diversidad dentro del grupo de académicas entrevistadas. Los criterios de exclusión de la muestra son: (1) administrativas, funcionarias $u$ otras personas que no desarrollen funciones académicas;

(2) académicas, docentes o investigadoras sin postgrado; (3) académicas a honorarios (profesores taxi); (4) académicos hombres.

1 Dando justicia a la diversidad de universidades en Chile (58 en total), se incluyeron en la muestra participantes pertenecientes a universidades públicas, universidades privadas tradicionales y nuevas universidades privadas. 
Tabla 1: Participantes

\begin{tabular}{|c|c|c|c|c|c|c|c|c|}
\hline ID & Universidad & $\begin{array}{c}\text { Área } \\
\text { académica }\end{array}$ & Jerarquía & Edad & Estado civil & $\begin{array}{c}\mathbf{N}^{\circ} \\
\text { Hijos }\end{array}$ & $\begin{array}{l}\text { Edad } \\
\text { hijos }\end{array}$ & Región \\
\hline 1 & Pública & $\begin{array}{l}\text { Ciencias So- } \\
\text { ciales }\end{array}$ & Asociada & 53 & Soltera & 0 & -- & Norte \\
\hline 2 & Pública & $\begin{array}{l}\text { Ciencias So- } \\
\text { ciales }\end{array}$ & Adjunta & 49 & Divorciada & 2 & 10,13 & Centro \\
\hline 3 & $\begin{array}{l}\text { Nueva Priva- } \\
\text { da }\end{array}$ & $\begin{array}{l}\text { Ciencias So- } \\
\text { ciales }\end{array}$ & Titular & 47 & Separada & 3 & $11,15,17$ & RM \\
\hline 4 & $\begin{array}{l}\text { Nueva Priva- } \\
\text { da }\end{array}$ & $\begin{array}{l}\text { Ciencias de la } \\
\text { Salud }\end{array}$ & Asistente & 41 & Casada & 3 & $6,10,12$ & Sur \\
\hline 5 & $\begin{array}{l}\text { Nueva Priva- } \\
\text { da }\end{array}$ & $\begin{array}{l}\text { Ciencias Bioló- } \\
\text { gicas }\end{array}$ & Asociada & 46 & Casada & 2 & 16,18 & RM \\
\hline 6 & $\begin{array}{l}\text { Privada Tradi- } \\
\text { cional }\end{array}$ & $\begin{array}{l}\text { Ciencias de la } \\
\text { Salud }\end{array}$ & Asistente & 43 & Casada & 2 & 8,15 & Sur \\
\hline 7 & $\begin{array}{l}\text { Privada Tradi- } \\
\text { cional }\end{array}$ & $\begin{array}{l}\text { Ciencias So- } \\
\text { ciales }\end{array}$ & Asistente & 41 & Soltera & 0 & -- & RM \\
\hline 8 & Pública & Humanidades & Titular & 45 & Separada & 0 & -- & Centro \\
\hline 9 & $\begin{array}{l}\text { Privada Tradi- } \\
\text { cional }\end{array}$ & Humanidades & Asociada & 44 & Casada & 3 & $1,5,7$ & RM \\
\hline 10 & $\begin{array}{l}\text { Nueva Priva- } \\
\text { da }\end{array}$ & $\begin{array}{l}\text { Ciencias So- } \\
\text { ciales }\end{array}$ & Asistente & 48 & Casada & 3 & $9,13,16$ & RM \\
\hline 11 & $\begin{array}{l}\text { Privada Tradi- } \\
\text { cional }\end{array}$ & $\begin{array}{l}\text { Ciencias So- } \\
\text { ciales }\end{array}$ & Asociada & 45 & Casada & 2 & 6,9 & RM \\
\hline 12 & Pública & Humanidades & Asociada & 48 & Conviviente & 2 & 18,21 & RM \\
\hline 13 & $\begin{array}{l}\text { Privada Tradi- } \\
\text { cional }\end{array}$ & $\begin{array}{l}\text { Ciencias de la } \\
\text { Salud }\end{array}$ & Titular & 41 & Conviviente & 0 & -- & Sur \\
\hline 14 & $\begin{array}{l}\text { Nueva Priva- } \\
\text { da }\end{array}$ & $\begin{array}{l}\text { Ciencias Bioló- } \\
\text { gicas }\end{array}$ & Asistente & 41 & Casada & 1 & 5 & RM \\
\hline 15 & $\begin{array}{l}\text { Privada Tradi- } \\
\text { cional }\end{array}$ & $\begin{array}{l}\text { Ciencias de la } \\
\text { Salud }\end{array}$ & Asistente & 39 & Casada & 2 & 3,6 & Sur \\
\hline
\end{tabular}

Fuente: elaboración propia

\section{Procedimiento}

El acceso a la muestra se hizo a través de contactos y redes de las investigadoras (técnica bola de nieve). A las entrevistadas se las invitó a participar a través de un correo electrónico, donde se les explicó el objetivo de la investigación y la solicitud de "enviarnos algunas fotos que mejor retraten su experiencia de teletrabajo académico durante la pandemia". Se recibieron 114 fotos en total, con un promedio de 7.6 fotografías por persona. Se les envió el Consentimiento Informado previamente por email, el que establece las condiciones 
de voluntariedad, anonimato y confidencialidad de los datos, con particular atención en el material visual. El consentimiento no fue firmado físicamente debido a la crisis sanitaria, sino que fue aprobado oralmente y grabada su aceptación. Para mantener el anonimato, las entrevistadas fueron asociadas a un ID de participante con sus características sociodemográficas (edad, área académica, jerarquía académica, situación de pareja, número y edad de los hijos, región, tipo de universidad). En las imágenes utilizadas por las investigadoras fueron borrados los rostros y elementos visuales que pudiesen identificar a las participantes (Papademas y International Visual Sociology Association, 2009). Esta investigación cuenta con la aprobación del Comité Ético Científico de la Universidad Finis Terrae.

\section{Resultados}

Las distintas realidades personales y familiares de las académicas han incidido en las variadas experiencias de teletrabajar durante la pandemia del COVID-19. Así como ocurre en el mercado laboral chileno, las trayectorias de las mujeres están definidas por la esfera reproductiva, que continúa siendo culturalmente signada femenina (Mora y Blanco, 2018). El trabajo doméstico y de cuidado establece experiencias decisivamente distintas y desiguales para las mujeres en el mercado del trabajo, y es también un factor clave de diferenciación entre mujeres. En torno al trabajo de cuidado, se (des)articula la trayectoria laboral de muchas mujeres en Chile (Undurraga y López Hornickel, 2021). Así, en nuestras participantes, factores sociodemográficos como tener o no hijos; las edades de los hijos; vivir sola o en pareja; además de la vivienda (departamento o casa), se han transformado en elementos relevantes para presagiar las diversas condiciones de trabajo y bienestar de las académicas durante la pandemia. En lo que sigue, se discuten algunas de las experiencias de teletrabajo de académicas en la pandemia, revelando similitudes y diferencias marcadas por la interconexión entre trabajo productivo y reproductivo.

\section{Online: extensión e intensificación del trabajo}

Para la mayoría de las participantes, el teletrabajo ha significado más trabajo, tanto por la extensión de la jornada como por una intensificación de las labores. Esto es transversal a las académicas, independiente de sus características sociodemográficas. Prescindir de traslados, tiempos muertos, momentos socializadores de la vida académica-como breaks en conferencias y en las labores académicas diarias, conversaciones de pasillos o intercambio con estudiantes- han modificado la rutina habitual de trabajo y los tiempos "no laborales" dentro del trabajo. Este "ahorro de tiempo" ha permitido una intensificación del trabajo que se refleja en poder atender a más reuniones en un mismo día y con personas de distintos lugares. Al no haber traslados, se puede finalizar una reunión y comenzar inmediatamente otra, reunirse con personas de otros países sin mediar lugar ni horarios. El omitir lo físico para reunirse, pareciera suponer mayor disponibilidad laboral y mayor seguimiento de tareas. Así lo plantean las entrevistadas ID3 e ID5: 


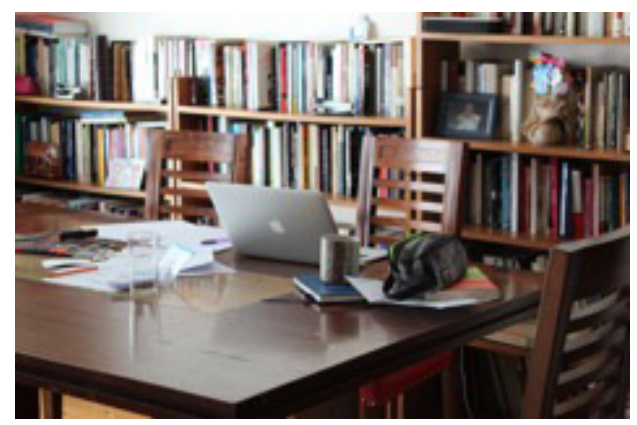

"Si es que era una reunión fuera de la oficina o si ibas a un seminario [antes de la pandemia], entonces ya, era todo el día o toda la tarde en el seminario, pero ahora las reuniones, no sé, parte a las cinco y es a las cinco o'clock, y eso te permite tener una reunión a las cuatro también y otra a las tres. Entonces como que te permite gestionar el tiempo de una manera mucho más eficiente y eso hace que uno tenga mucho más disponibilidad para reunirse y más reuniones. Es más trabajo porque tienes que dar seguimiento a más cosas. (...) se ha ido intensificando, en términos de reuniones. Puede ser porque estoy con mucho proyecto, pero con quien hablo es como que tiene la misma sensación, de que se ha incrementado la intensidad del trabajo" (ID3, profesora titular, ciencias sociales, 47 años, separada, 3 hijos de 11, 15 y 17 años).

"En papel, el teletrabajo es cuando tú tienes un horario żya? Estipulado, con ciertas pautas, reuniones fijas, que tiene una estructura, en donde tú tienes más encima un espacio dirigido y exclusivo para el trabajo. En donde, no sé poh, partiste a las 8:30 y terminaste a las 5:30, se cumplen esos horarios. Hoy en día, el trabajo en la casa no tiene un horario establecido porque ni siquiera se respetan los horarios del almuerzo, porque te llaman justo en ese momento porque claro, a todos nos han llenado de reuniones porque existe la falsa sensación de que como cuando uno está en la casa hace menos cosas, eh... las jefaturas tienden a sobrecargarte con labores, desde el punto de vista administrativo o reuniones" (ID5, profesora asociada, ciencias biológicas, 46 años, casada, 2 hijos de 16 y 18 años).

Los tiempos de trabajo han aumentado para lograr resultados de calidad cuando el tiempo "oficial" no es suficiente para alcanzar lo comprometido. El hecho de que las clases y reuniones sean online, ha demandado más preparación y trabajo, exposición a pantallas y esfuerzos para interpretar a los interlocutores sin las señales corporales no verbales propias de la interacción presencial. Si bien el teletrabajo permite trabajar en cualquier horario y lugar -si las condiciones personales y familiares lo permiten- también demanda mayor disponibilidad y flexibilidad de tiempo, y la adquisición de nuevas habilidades técnicas y de docencia, lo que se ha traducido en una mayor carga laboral y más horas de trabajo para las académicas. La ausencia de un espacio y tiempo definido para trabajar ha convertido el trabajo en una constante. El teletrabajo y las TICs permiten ir y venir, en distintos lapsos, al mundo laboral; junto con tener el material de trabajo todo el tiempo a la vista, resulta en jornadas continuas o "trabajar lo más que se pueda" para avanzar en aquello inconcluso. Las responsabilidades académicas parecieran estar adosadas a la vida en su totalidad, como relata la entrevistada ID4:

"... además que uno está todo el día disponible, o sea, porque tienes el computador al lado y, lo otro (...) a la pega que uno tiene regularmente, ahora se suma la urgencia de revisión de los proyectos COVID, entonces esa cuestión te demanda. A mí me citaban a reunión extraordinaria tres veces a la semana. (...) Yo creo que trabajo 
más fijate [en pandemia] porque como tengo el computador aquí (...) entonces de repente uno tiene un tiempo y ipum! me voy a terminar esta cuestión porque me faltó un poquito. En cambio, claro, cuando tienes la oficina, yo trataba... antes me traía mucha pega, pero trataba, bueno en general, siempre me traigo los proyecto para revisar, yo reviso en la noche porque no me alcanza el tiempo, entonces estoy así (somnolienta), siempre en las noches leo eso, ahora tengo todo el día, pero yo creo que me ha aumentado la pega porque la tengo todo el rato disponible, está abierta ahí, entonces bajo, no sé, a buscar algo y voy a aprovechar o ver si me mandaron alguna cosa y ya, me pongo de nuevo [a trabajar]" (ID4, profesora asociada, ciencias de la salud, 41 años, casada, 3 hijos de 6, 10 y 12 años).

La carga laboral ha aumentado. Además, de manera tangible como consecuencia de incipientes reducciones presupuestarias en las universidades a raíz de la pandemia, algunas participantes dan cuenta de una mayor carga docente como una "estrategia" de ahorro anticipado para las universidades, que han prescindido de docentes externos y de planta:

"A propósito de los problemas económicos actuales o que se prevén para el próximo año, resulta que, claro, tenemos que tomar ahora actividades que no hacíamos antes; por ejemplo, yo no acompaño a los internos, yo no, hago muy poco eso y ahora, como además están tele-atendiendo he tenido que tomar actividades de tele-atención con internos y con alumnos" (ID6, profesora asistente, ciencias de la salud, 43 años, casada, 2 hijos de 8 y 15 años).

\section{Labores simultáneas}

La intensificación del trabajo se expresa en la simultaneidad de tareas. El uso de las TICs permite -y en ocasiones exige- estar en más de una actividad a la vez. La siguiente foto y relato retratan esta experiencia para la académica ID 14.

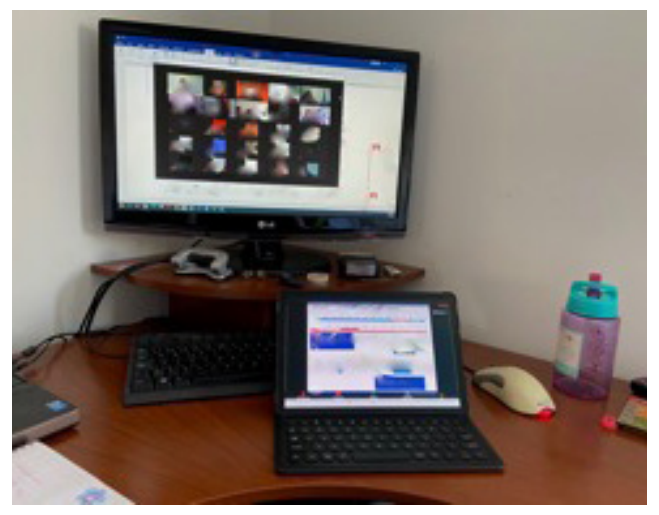

"Con esto del teletrabajo, aumentó el número de reuniones y hoy tengo el doble de lo que tenía antes. Entonces este era un ejemplo de un día que me tocaba ser moderadora de una charla, que es lo que estoy viendo en el Tablet, que está ahí abajo, y me tocaba reunión del Instituto Milenio al mismo tiempo, a la misma hora. Sí, entonces estaba atenta abajo, alguien estaba presentando, pero cuando la persona terminaba de presentar, yo tenía que agradecer y guiar las preguntas. Y en el otro [computador] era una reunión científica del Instituto, que también alguien estaba presentando su trabajo. Sí, porque eso ya fue como extremo. Claro, porque ella [hija] al lado de este escritorio, que sale en la otra foto, le instalé su escritorio también" (ID 14, profesora asistente, ciencias biológicas, 41 años, casada, 1 hija de 5 años). 
Esta imagen, explica la participante ID14, documenta un momento álgido de su experiencia de teletrabajo. Modera un seminario en zoom y participa en una reunión de un grupo de investigación a la vez, teniendo en todo momento a su hija de 5 años sentada en la extensión de su escritorio. Esta simultaneidad de actividades que intensifica el trabajo es particularmente "realizable" con la disponibilidad de gadgets tecnológicos. Asimismo, la entrevistada ID 11 relata cómo los audífonos inalámbricos que adquirió durante la pandemia le permiten estar en varios frentes del trabajo universitario y del trabajo de cuidado a la vez.

"Los compré [audífonos inalámbricos] en medio de la pandemia. Entonces a ellos [hijos] les compré unos auriculares con cable que además permiten poner el cable para que yo tenga auriculares, porque mi hijo ya está en tercero básico y está más solo en las clases, pero mi hija, en especial el primer semestre estaba aprendiendo a leer, a sumar, a escribir. (...) Yo estoy acá, lista igual acá con estos inalámbricos [muestra audífonos], entonces si él [hijo de 9 años] necesita algo, apago el video acá, igual escucho lo que pasa alrededor de FONDECYT, voy y lo ayudo. (...) A mí me salvó la vida, porque por ejemplo, él [hijo] puede estar en clases en la cocina, pero mi hija todavía la limpio cuando va al baño, entonces me puede llamar, y entonces apago la cámara del video, voy, la limpio, y al mismo tiempo estoy en la reunión" (ID1 1, profesora asociada, ciencias sociales, 45 años, casada, 2 hijos de 6 y 9 años).

\section{Grabando... docencia en línea}

El cambio de la sala de clases al aula virtual a través de plataformas en línea también ha significado una intensificación del trabajo. Las exigencias pedagógicas de la docencia virtual son muy diferentes a la docencia presencial. La docencia en línea implica tareas simultáneas y atención a múltiples focos, como presentar, responder el chat de los estudiantes, considerar asuntos técnicos de conexión y plataformas, además de ocuparse del contenido, lo visual y promover la interacción oral. Asimismo, hay una serie de ajustes a la modalidad online tanto del material presentado en clases, actividades y bibliografía, como de las rúbricas y evaluaciones. A eso se agrega la necesidad de pre-grabar clases o cápsulas de video, tareas que en caso de madres académicas con hijos pequeños se tienden a hacer en horario nocturno cuando hay menos interrupciones, como un reciente estudio cualitativo en Italia y Estados Unidos constató (Minello, Martucci y Manzo, 2020). El aumento de trabajo en docencia se muestra también entre las entrevistadas de nuestro estudio.

"Entonces ese trabajo previo es mucho [preparación de clases]. Porque claro, yo tenía mis clases y además soy bien estructurada, yo muchas de las clases las tengo escritas (...) Pero igual, así y todo, cuando tú lo haces presencialmente hablas mucho rato, pero acá no podí dar la lata, tiene que ser un contenido condensado y claro. Además, tenís que buscarte una imagen chora (...) hago gráficos, o sea, diagramas más bien o si no, pongo la portada del libro o una foto del autor o la autora, o sea, como una cuestión más visual, entonces tenís que buscar eso, armar eso, entonces eso es mucho más preparación. (...) mis clases, los textos o cualquier otro recurso queda colgado en el aula virtual (...) yo te diría que la preparación es mucho mayor" (ID2, profesora titular, ciencias sociales, 49 años, divorciada, 2 hijos de 10 y 13 años). 
En la modalidad online, la ausencia de interacción cara a cara se agrega al creciente reemplazo de la comunicación oral por el chat escrito en las plataformas de docencia. Según la entrevistada ID 14, esto la ha llevado a ocupar dos computadores a la vez durante sus clases: uno para mostrar su presentación de power point y otro para seguir el chat de los alumnos, sin la necesidad de cambiarse de pantallas. Además, la mayoría de los estudiantes mantienen sus cámaras apagadas, por problemas de conexión, pudor de su entorno, desidia u otras razones. Esto implica dar clases frente a una pantalla negra, a una lista de usuarios o mirando la propia presentación. La interacción entre profesora-estudiante y entre compañeros en las plataformas de docencia es limitada y dificultada por la imposibilidad de leer códigos no verbales. Esta experiencia es relatada por la participante ID 12 y que representa con la foto a continuación:

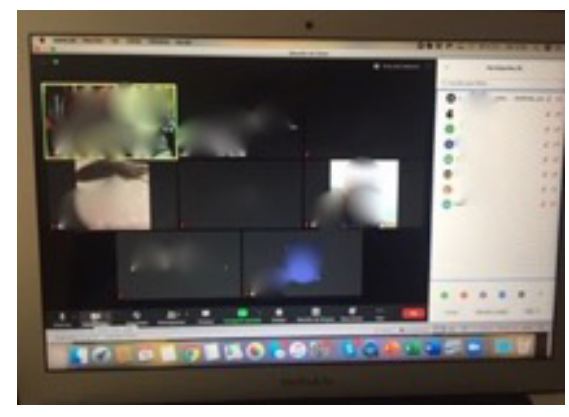

"Yo creo que de las cosas difíciles, han sido las clases de pregrado como ahora. Esta foto es de un curso que estoy haciendo ahora de teoría, a estudiantes de primer año que, como ves, en general, nadie tiene la cámara prendida, salvo una chica, entonces es una experiencia compleja, o sea, complejo enseñar teoría a un curso en que uno no ve las caras, no tiene como todas las dimensiones eh... de otros lenguajes, también para el feedback ¿̇no?" (ID 12, profesora asociada, humanidades, 48 años, convive, 2 hijas de 18 y 21 años).

\section{En escena: el trabajo reproductivo}

El confinamiento por la pandemia y el cierre presencial de colegios y jardines infantiles han significado que todos los integrantes del grupo familiar estén compartiendo y compitiendo por un espacio físico dentro del hogar para desarrollar sus labores. La presencia continua de adultos y niños ha traído, además, un aumento de demandas de contención emocional, de acompañamiento en la instrucción escolar de los hijos y de tareas domésticas, a las que se han agregado las medidas de higiene y sanitarias para evitar el coronavirus. Los arreglos cotidianos en la distribución del espacio y el crecimiento de la carga total de trabajo, especialmente para las mujeres (Bravo, Castillo y Hughes, 2020; ONU Mujeres, 2020), han traído como consecuencia una evidente tensión entre el trabajo remunerado y el no-remunerado. Particularmente en el caso de académicas con hijos pequeños o dependientes y para jefas de hogar, la sobrecarga laboral, emocional y doméstica, ha generado una sensación de desborde, sobre todo entre aquellas que son las únicas adultas responsables de menores y proveedoras de lo material. Esta imagen de ID3 y su relato, resumen su experiencia: 


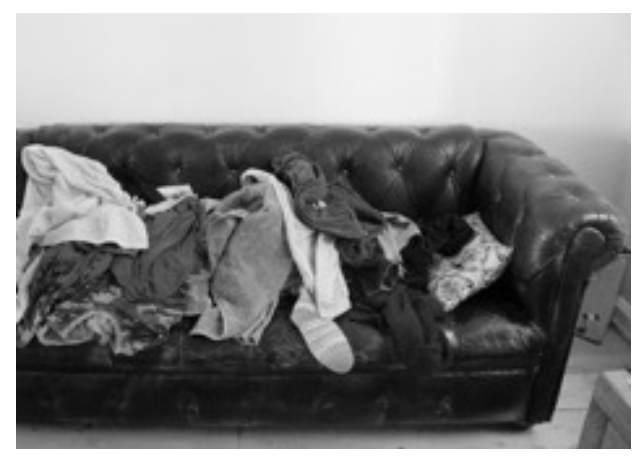

"... uno tiene como en la cabeza la familia ideal y la familia real que uno tiene. Entonces en la familia ideal, todo el mundo se hace cargo de sus cosas y todos ayudamos y lavamos entre todos y ordenamos entre todos, que es lo que trato de enunciar muchas veces con los niños. Y al principio de la pandemia (...) cada uno una función, pero al poco andar, no se instala como un hábito. Entonces, es como que permanentemente el desborde por algún lado: de desorden, de desestructura, de desorganización. Yo creo que esa foto refleja como esos desbordes. De aquello que uno quiere tratar de mantener así, súper, no por la familia ideal, sino por sanidad mental mía. Porque si no, no funciona, no funcionamos, pero finalmente, también la exigencia de mantener esa estructura me termina en contra de mi propia salud mental porque implica que uno tiene que estar żordenaste? $\dot{2}$ limpiaste? ¿̇viste? Y si no lo hago, entonces queda al final eso, eh... pero como no lo puedo hacer porque estoy trabajando y estoy así como full. (...) eso es como la acumulación también de esa estructura y que al final es como aceptar no más que es así. Como tratar de verlo en el sentido de que es imposible simplemente; es imposible mantener toda esa organización así tan fantástica" (ID3, profesora titular, ciencias sociales, 47 años, separada, 3 hijos de 11, 15 y 17 años).

El desborde por las exigencias del trabajo productivo y reproductivo en pandemia también lo manifiesta la participante ID9 a través de las imágenes y el relato a continuación:
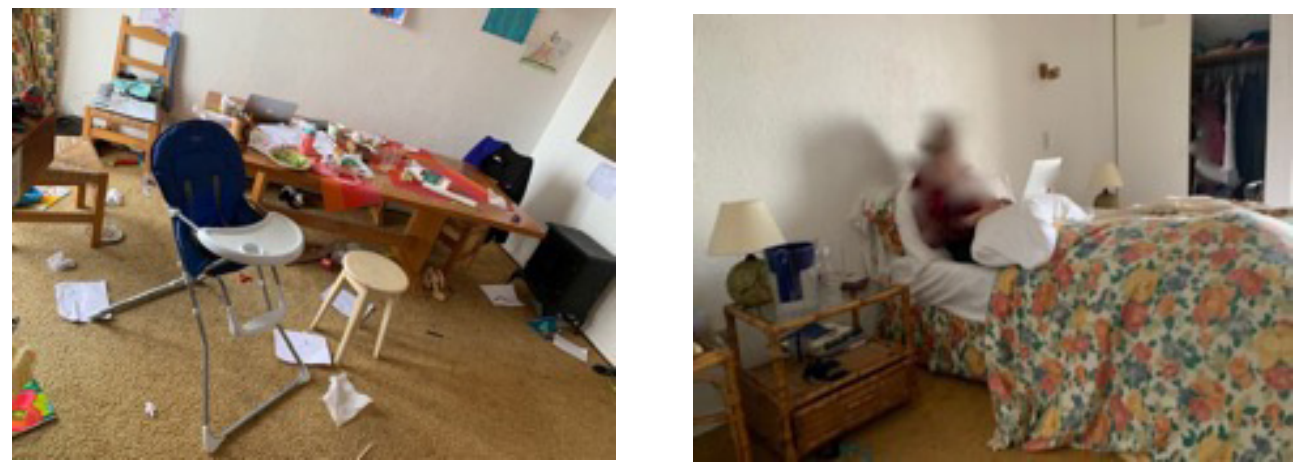

"Hay muchas actitudes muy antiguas, que todavía sobreviven en ese rincón de la academia. Y en la reunión, la mayoría estaba hablando de una manera muy calmada de cómo podemos perfeccionar nuestra enseñanza en el modo virtual y yo empecé a casi eh... casi tuve un ataque de pánico, sintiéndome que yo vivo en un mundo tan aparte, en un mundo tan invisible, invisibilizado para ellos, que me sentía invisibilizada $100 \%$, que casi empecé a llorar. Yo estoy muy lejos de poder hablar de cómo poder perfeccionar mis enseñanzas virtuales, estoy muy muy lejos de... mi lucha cada día es meramente aparecer frente a la pantalla sin tener a alguien gritándome, interrumpiéndome, creando condiciones bajo los cuales simplemente no se puede dar un curso, no se puede dar una charla, no se puede dar una clase... y acarreando estas condiciones de manera permanente, sin fin, día a día, 24 horas, semanas, mientras ya, y luego el almuerzo, luego la limpieza y luego lavar la ropa y fue una crisis muy 
heavy. (...) La crisis del COVID me ha convertido en profesora de la escuela primaria de mis hijas, estando en casa a tiempo completo, cocinar, ser limpiadora, niñera, cuidadora de niñas, etcétera. Mi trabajo a tiempo completo como académica se ha reducido a una idea de último momento. Intento desesperadamente tomar 10 a 15 minutos aquí, allá para preparar clases entre las labores de la comida, de la limpieza, el cambio de pañales, las pataletas de las niñas, la siesta para mi hija, etcétera. Esto sin mencionar las extraordinarias demandas psicológicas que las niñas y niños de todo el mundo están imponiendo a sus padres a la luz de la cuarentena y de la crisis de salud a la que responden" (ID9, profesora asociada, humanidades, 44 años, casada, 3 hijas de 1, 5 y 7 años).

\section{Naturalizar el género}

La sobrecarga laboral, emocional, doméstica y de cuidados es evidente entre muchas participantes. Los testimonios muestran que estas labores son asumidas como responsabilidad, en su mayoría, de las mujeres, es decir, su no cumplimiento es una falta de ellas (Sharma, 2020). Para algunas, esto se justifica por la condición natural de mujer que le permitiría hacer varias cosas a la vez. Para otras, esta carga implica asumir un espacio de trabajo compartido con los hijos, mientras la pareja heterosexual teletrabaja en un lugar más privado. Entre las primeras, ID4 expresa esta capacidad femenina de lidiar simultáneamente con el teletrabajo y las atenciones que sus hijos menores requieren.

"Mami, ¿̇cómo me quedó este mono?, ¿PPuedo pintar?, qué se yo y él [hijo] tiene sus cosas aquí atrás, y pinta y todo (...) o saluda a la cámara, pero yo trabajo con todos (...) Cuando uno es mujer, tiene la capacidad de hacer varias cosas a la vez, sin necesidad de desconcentrarte. Yo puedo estar haciendo concentrada una cosa, 'sí, está lindo las rayas, te faltó esto' y sigo súper concentrada igual" (ID4, profesora asistente, ciencias de la salud, 41 años, casada, 3 hijos de 6, 10 y 12 años).

El lugar de trabajo que ocupa cada persona dentro de la casa también muestra las relaciones de poder entre los integrantes del hogar: quién elige, quién cede, quién controla. Esto según las posibilidades y constricciones del espacio físico. Con todo, no es casual que muchas mujeres trabajen en el comedor o en espacios abiertos donde se desarrolla la vida del hogar, particularmente, para poder ver y atender a los niños, mientras que los hombres -en el caso de hogares que habiten parejas heterosexuales- disponen de un lugar alejado o con puerta donde efectivamente puedan trabajar sin interrupciones domésticas. La misma entrevistada continúa:

"Conversábamos con una amiga, el otro día, la diferencia entre el teletrabajo del hombre y la mujer: él está en una pieza de visitas que tenemos arriba, en un escritorio, con todo, está la impresora, todo, todo y con la puerta cerrada y ahí trabaja. ¿̇Te fijas? Yo estoy aquí, tenemos un escritorio abajo, que es una pieza de estudio, donde aquí, más atrás, ahí está el computador de mi hijo, que subió a buscar algo, el de 10, tengo una mesa redonda para hacer las tareas, donde se sienta el chico y yo estoy en mi escritorio acá. Entonces, entra uno, sale otro, se me pasean. (...) Una amiga igual me contaba, que ella es abogado y el marido igual, pero el marido se va a trabajar al quincho afuera, encerrado, nadie lo ve, lejos, fuera, y ella igual está con los niños en el mismo lugar, pasa uno, sale otro y les pasaba a todas lo mismo" (ID4, profesora asistente, ciencias de la salud, 41 años, casada, 3 hijos de 6, 10 y 12 años). 
La transformación artesanal de espacios que originalmente cumplían otras funciones (dormir, comer, compartir, descansar, estar) en zonas de trabajo, en el caso de académicas con hijos pequeños además va aparejada de la creación de ambientes donde los hijos se integran en la cercanía inmediata de la madre para hacer sus tareas o jugar. Varias participantes con hijos pequeños comentan tenerlos en su misma mesa, como muestra la siguiente foto de ID15 (profesora asistente, ciencias de la salud, 39 años, casada), donde sus hijos de 3 y 6 años trabajan o juegan a su lado, en la prolongación del escritorio que ella misma armó a raíz de la pandemia: "Ese es mi rincón de improvisado estos meses para poder trabajar".

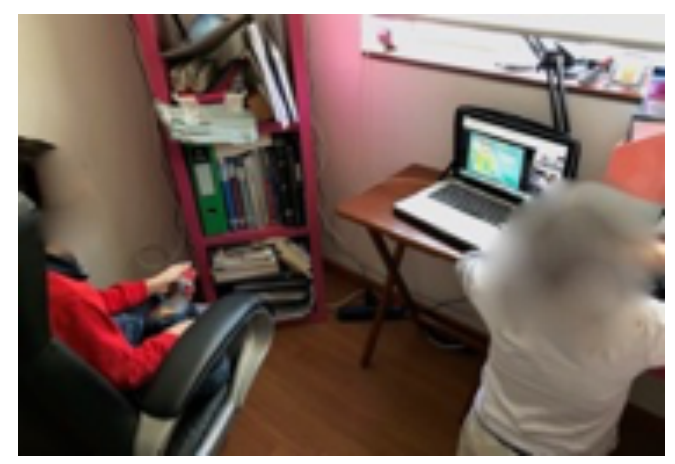

La modificación de espacios del hogar en zonas de trabajo no sucede solamente en función del trabajo, sino también en razón de los hijos y de la multifuncionalidad de las labores cotidianas. Las condiciones de los ambientes adaptados al trabajo son, además, a menudo inhóspitas. Varias entrevistadas relatan trabajar en condiciones precarias o incómodas: conexión a internet inestable, sillas duras, escritorios pequeños y plegadas a otros elementos.

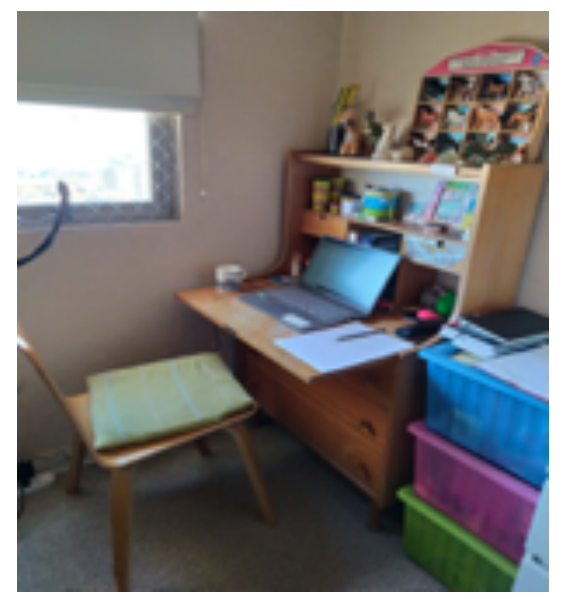

"Bueno, eso estaba mostrando ahí, donde trabajo, que supongo que se ve que es la pieza de los niños. O sea, el escritorio de los niños, están todos los juguetes, es su escritorio chico" [mientras sus dos hijos atienden clases virtuales escolares desde la mesa del comedor] (ID2, profesora titular, ciencias sociales, 49 años, divorciada, 2 hijos de 10 y 13 años). 
La distribución de los espacios y de las herramientas de trabajo nos hacen pensar también en el hecho de que una pieza para una misma, en el sentido de Virginia Woolf, parece ser una melodía lejana para muchas académicas en tiempos de pandemia.

\section{Investigar y escribir: ¿cuándo?}

La pandemia y el giro hacia el teletrabajo ha trastocado el orden de las prioridades académicas, centrándose en las labores posibles: docencia, gestión y, por último, investigación, que es la "mercancía" más valorada en las universidades (Mandiola, Ríos y Varas, 2019). Los efectos de la pandemia para el ámbito de la investigación son diversos, tanto en términos de productividad como de presupuesto. Respecto a las posibilidades para investigar en tiempos de pandemia, se pueden distinguir dos grupos de académicas: uno, aquellas con hijos pequeños y/o jefas únicas de hogar y, dos, académicas con hijos mayores o sin hijos.

\section{En la noche}

En el primer grupo de académicas, las tareas de cuidado y el trabajo doméstico implican interrupciones constantes durante su jornada para atender las necesidades de sus hijos: escuela online y tareas de los hijos, preparación de alimentos, contención y entretención, entre muchos otros. Todo esto, sumado a la sobrecarga del trabajo docente, redunda en que la investigación solo puede realizarse por lapsos breves o después del término de la jornada laboral y de cuidado: en las noches. La falta de tiempo para la investigación se vive con ansiedad por las académicas. Como plantea ID14 (profesora asistente, ciencias biológicas, 41 años, casada, 1 hija de 5 años), con la pequeña a cargo y un marido teletrabajando encerrado y absorto, la investigación y preparación de clases y artículos, que exigen concentración, se trasladaron a su turno nocturno, entre las 21.30 y 00:30 hrs. "Varios días tuve que hacer ese horario, entonces, como te decía, es como un continuo entre, como que no sales del trabajo nunca, como que se vuelve el trabajo, la casa, no hay una diferencia". Ella comparte esta imagen que representa sus largas jornadas:

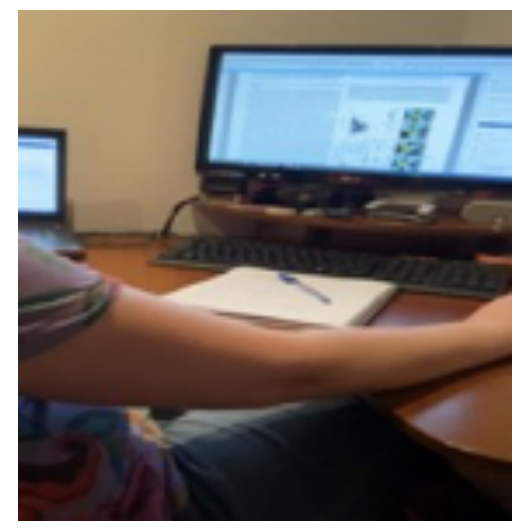


Para las académicas del primer grupo (con hijos pequeños), el teletrabajo durante la pandemia significa un gravamen a la productividad futura y no necesariamente a la actual. Por ejemplo, la participante ID 1 plantea que lo publicado este año, en pandemia, es consecuencia de manuscritos enviados con anterioridad:

"Y fue difícil, yo en estos meses, mandé un paper sola, que no sé qué pasó con ese paper, pero también tuve suerte que salieron algunos papers que habíamos mandado antes, pero es engañador porque si ves mis resultados, dices ay, por ahí publiqué más que otros años, pero no es que trabajé más que otros años. Se dieron un montón de otras circunstancias que hicieron que salieran más papers publicados que en otros momentos, así que si lo empiezan a medir así, van a empezar a decir: 'pero hay mujeres que les fue súper bien y no tuvieron ningún problema' y no, no es así. Seguí comprando libros, seguí tratando de leer algunas más cosas, pero así, no, no es lo mismo. El problema va a ser cómo van a medir este impacto en la investigación, porque yo creo que, en mi caso, se va a ver en dos años. No se va a ver este año, y bueno, eso es algo que me preocupa igual" (ID 1 1, profesora asociada, ciencias sociales, 45 años, casada, 2 hijos de 6 y 9 años).

Algo muy similar plantea ID15, quien cree que el efecto real de la pandemia en la baja de la productividad en investigación de académicas se va a ver en el año 2021 y adelante. Sobre sus posibilidades de hacer investigación y su productividad, reflexiona:

\begin{abstract}
"Más o menos porque si ya logramos hacer, como con todo el esfuerzo, lograr hacer la docencia, es difícil también lograr en el otro ámbito. Eh bueno, yo tenía una publicación que venía eh... no pudiendo publicarla y se publicó en marzo de este año (...) y de ese mismo trabajo me quedaron datos que, en realidad, no tenían relación directa con el objetivo de esta publicación. Así que, actualmente, estoy trabajando en poder publicar esos datos que me quedaron (...) pero otra cosa o pensar en postular un proyecto, por ejemplo, uh para mí, en estos momentos, es como impensado. No, no logro visualizar poder pensar en postular a algún fondo o algo, no" (ID15, profesora asistente, ciencias de la salud, 39 años, casada, 2 hijos de 3 y 6 años).
\end{abstract}

\title{
Sin interrupciones
}

Para el segundo grupo de académicas, aquellas sin hijos o con hijos mayores, el teletrabajo no ha tenido el mismo impacto en la investigación y productividad. Al contrario. Para ellas, teletrabajar ha significado desarrollar estas labores sin interrupciones: estudiantes y asuntos no-académicos de la universidad han desaparecido. Trabajar desde sus casas les ha permitido leer y escribir en bloques de tiempo más prolongados y sin intervalos externos, favoreciendo la creatividad y concentración necesarias para el proceso de preparación de manuscritos. Lo que une a estas académicas es que han definido un espacio particular para trabajar desde la casa, y sienten que tienen lo necesario para poder hacerlo: sus libros, computador, comodidad y silencio. Continuarían teletrabajando posterior a la pandemia, ya que pueden investigar y escribir sin grandes contratiempos, más allá de la incertidumbre producto de la crisis sanitaria. 
"La verdad es que he podido escribir bastante, a diferencia de lo que dicen otras personas, como sobre todo en relación a mujeres y trabajo y cuestión doméstica. Como mi situación familiar con mis hijas es como fácil, digamos, y normalmente tengo muchos viajes, tengo mucho movimiento, ahora el hecho de estar más en la casa y quieta me ha dado un poco más de tiempo para leer, para escribir" (ID12, profesora asociada, humanidades, 48 años, convive, 2 hijas de 18 y 21 años).

\section{La soledad: el otro lado de la pandemia y el teletrabajo}

Durante la pandemia, relativa atención se le ha puesto a las consecuencias emocionales y en salud mental que podría provocar la soledad en personas mayores (Pinazo-Hernandis, 2020). Profesionales con trabajo serían parte del grupo de los privilegiados. Por tanto, no se ha abordado en su total magnitud lo que ha implicado la soledad y el aislamiento para quienes han trabajado durante ocho meses o más sin salir de sus casas. Este es el caso de algunas participantes, sobre todo aquellas que viven solas, pero también para quienes sienten resquebrajada la naturaleza social del ser humano y debilitados los beneficios de la necesaria retroalimentación en el trabajo académico. Así lo expresa una académica que vive sola:

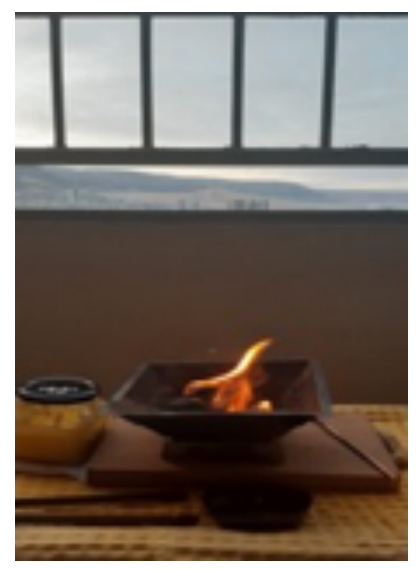

"Mira, yo creo que la soledad [mayor desafío del teletrabajo]. Porque estás sola haciendo el trabajo, no tienes con quién interactuar, no tienes con quién conversar, porque si estabas en el trabajo, tú hacías una pausa, te encuentras con colegas, estás con la secretaria, los estudiantes (...) o te vas a comprar un café (...) te encuentras con personas, entonces puedes ir haciendo pausas que tienen como algún contenido más significativo en lo social; el ser humano es un ser social. Y aquí eso ha estado coartado y yo creo que eso nos ha afectado de manera que ni siquiera sospechamos. (...) tampoco tienes todos los conocimientos de cómo afecta la falta de relación social a la persona, pero es obvio, que si tú tienes más estimulación por el hecho de que te juntas con los colegas, 'mira yo he pensado esto sobre una entrevista' y el otro te retroalimenta y te sientes más energizada. Yo creo que aquí se ha producido una especie de cansancio general, una especie de aletargamiento y del que no somos conscientes (...) porque tienes todas las relaciones sociales paralizadas" (ID1, profesora asociada, ciencias sociales, 53 años, soltera, sin hijos). 
La soledad del trabajo académico y la soledad personal se mezclan y profundizan durante la pandemia. Las académicas que viven solas reflexionan sobre la necesidad de desarrollar estrategias para sobrevivir el confinamiento en soledad, así como sobre los costos personales de la vida dedicada a la academia. La participante ID7 (profesora asistente, ciencias sociales, 41 años, soltera, sin hijos) comenta sobre su decisión de autocuidado, que involucró bajar la auto-exigencia durante el confinamiento:

"La primera semana de cuarentena me senté conmigo misma un minuto y dije: ¿Qué va a ser lo prioritario durante este tiempo en pandemia, en soledad, en cuarentena? Sobrevivir y sobrevivir sana, así que, ¿̇qué tienes que hacer? ¿̇Qé tengo que hacer para estar bien yo, para sobrevivir emocionalmente este tiempo en soledad? Que iban a ser... yo sabía que iban a ser varios meses por una cuestión de Europa, entonces, comencé, compré helado, compré cosas como ricas para comer... como que todo lo que me significaba algo que me dé placer en la comida, estaba y está. El pilates y yoga no los podía dejar, entonces, me unía a mis clases online que ya las tenía de antes, pero no era online, antes eran presenciales, y mi terapia, y producir en la medida en que yo sintiera que iba a poder ¿̇cachai? Entonces me dediqué a escribir un libro que tengo que entregar, pero sin esa presión de que la productividad, para mí, algo que sí tenía antes, era lo más importante en este tiempo. Pero tiene que ver con una decisión de autocuidado mía, y que yo no lo veo en mis colegas y que no lo tenía antes, y que fue una decisión de que, si voy a vivir en una pandemia, no me voy a volver loca (risas), de no volverme loca.

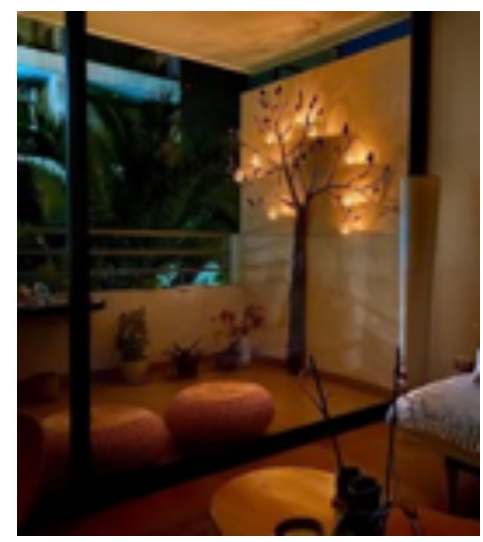

... me quedé ahí sentada y me puse a pensar en eso, como en este desafío de vivir un trabajo académico que, en general, es solitario, y que, en general es invisible esa soledad, y que también significa... Tengo 41 años, pero he decidido principalmente, he seguido una vida académica súper, súper potente e interesante para mí, pero que significa un costo en lo personal súper fuerte" (ID7, profesora asistente, ciencias sociales, 41 años, soltera, sin hijos).

El distanciamiento físico y el aislamiento social por completo no son convenientes. Tampoco para la academia. A pesar de que la academia es una actividad más bien solitaria, la retroalimentación e intercambio entre pares es fundamental para el proceso productivo. A esto se añade la soledad del cotidiano vivir en un confinamiento de largos meses. 


\section{Diversidad de realidades, pero homogeneidad de políticas}

Las exigencias académicas y laborales se han mantenido: docencia, investigación y metas productivas. Es más, durante la pandemia, las docentes se han visto sobre-exigidas para incorporar nuevas metodologías de enseñanza, dictar clases online a estudiantes sin rostro, participar en webinars, mientras los estándares de publicación y adjudicación de proyectos no se han visto alterados. La mayoría de las universidades chilenas no ha considerado la diversidad de realidades personales y familiares entre sus colaboradores, que garanticen condiciones laborales y criterios de evaluación adecuadas para hacer del teletrabajo algo posible y grato. Las realidades personales son diversas, pero los resultados exigidos son los mismos. De siete universidades empleadoras de las académicas entrevistadas, cinco no han desarrollado políticas de teletrabajo ni tampoco en relación al efecto del género en las experiencias y trayectorias de sus académicos.

"La universidad, de verdad, no creo que haya tomado las medidas suficientes (...) A lo más, esta llamada por teléfono o capacitación para usar Zoom o extender el semestre para los estudiantes, pero yo creo que deberían haberse bajado las exigencias; hasta FONDECYT dio la posibilidad de ajustar los proyectos ino? De cambiar metodología, de reducir objetivos, de extender plazos, pero la universidad no lo hizo. Y sigue todo igual y siguen las exigencias igual y los plazos siguen igual (...) que cada jefatura debería haber tenido... pero eso tendría que haber partido de arriba, pero de arriba no... qué están tan... con la situación de la universidad ¿no? Pero debería haberse implementado que cada jefatura hubiese sostenido alguna reunión. Hey, esto es una situación que afecta, porque como te digo, o sea, sí afecta de manera insospechada" (ID 1, profesora asociada, ciencias sociales, 53 años, soltera, sin hijos).

La mayoría de las instituciones universitarias han intentado, en lo posible, suplir las solicitudes formales puntuales: un computador, una silla, conectividad, una situación extraordinaria de cuidado. Sin embargo, estas no han sido medidas aplicables para todos. Pareciera regir el "caso a caso" en vez de una política propositiva para los teletrabajadores.

"La universidad, en ningún momento, nadie me preguntó si yo tenía computador, si no tenía computador para trabajar. Sé que mucha gente, para trabajar, tuvo que ir a buscar su computador y pudo hacerlo, pero no fue una política generalizada. Yo misma, yo como directora tuve que gestionar para una de las secretarias que le facilitaran su computador y algunos otros elementos esenciales, porque ella en su casa no los tenía, ¿̇ya? Yo creo que no, no han tenido una política clara, no ha sido proactiva; en eso ha sido reactiva. Ahí se generan un montón de inequidades, porque hay mucha gente que es mucho más de arreglárselas sola ¿me entiendes?, porque puede sufrir después las consecuencias, pero es un tema. Y ahí se induce un tema de género, porque las mujeres son más de comérselas, de tratar de no generar problemas versus los hombres" (ID10, profesora asistente, ciencias sociales, 48 años, casada, 3 hijos de 9, 11 y 15 años).

A falta de una política institucional, las universidades han reaccionado parceladamente frente a requerimientos individuales, normalmente de académicas con hijos pequeños que han visto sus límites emocionales y laborales extrapolados. Se resuelve entonces el "problema de género" a nivel individual y puntualmente, pero sin una política institucional que 
transforma una solicitud en un derecho. En general, no hubo concesiones, a excepción de una participante (ID5) que reconoció flexibilidades horarias para quienes tienen dependientes a su cargo en esta pandemia, resolviendo caso a caso las necesidades particulares en los equipos de trabajo. Otra académica (ID2) relató haber intercedido para que ello ocurriese en su departamento, sin mayor apoyo de colegas hombres ni de las autoridades. Y solo una de 15 participantes manifestó haber reducido su carga laboral (tras conversaciones y carta al Decano), como relata a continuación:

"Él [Decano] respondió muy bien y cambió la política, me sacaron la enseñanza. Este semestre no he tenido enseñanza que fue la clave, la clave de nuestra recuperación, salimos de un modo de crisis, pudimos normalizar nuestras relaciones dentro de la casa, nuestra vida cotidiana, día a día, fue absolutamente clave, eso fue un triunfo y yo estaba muy orgullosa, muy contenta, porque además, fue muy importante para mí que él no viera estas peticiones, esta solicitud, este acto de sacar la enseñanza como un favor personal para mí. Me interesaba muchísimo que era una decisión tomada por principios y que ofrecieran lo mismo a los demás en mis condiciones, a los otros académicos que estaban en mis mismas condiciones, porque no cachar el asunto de la justicia al fondo, me molestaría" (ID9, profesora asociada, humanidades, 44 años, casada, 3 hijas de 1, 5 y 7 años).

A pesar de los graves estragos presentes y futuros en las trayectorias laborales de académicas producto de la pandemia, las instituciones de educación superior chilenas no han tomado políticas de género que permitan a sus colaboradores, en situaciones personales complejas, poder efectivamente lograr lo encomendado. Menos aún oportuno, aumentar la carga docente, como ha sucedido en algunos casos. Ante una nueva ola de coronavirus y otro periodo de cuarentena, las universidades aún están a tiempo para anticipar medidas que permitan desarrollar el teletrabajo en condiciones materiales y estructurales adecuadas, y considerar el apoyo emocional y de salud mental que sus colaboradores puedan necesitar ante una crisis de esta magnitud. Hasta ahora, se han implementado acciones para capacitar al plantel docente para extender sus capacidades a la metodología virtual, medidas fugaces relativas al bienestar y salud -como webinars sobre estilo de vida saludable y capacitación sobre el coronavirus y protocolos de higiene- y, en un caso, una llamada desde la universidad para conocer la situación de contagio entre sus colaboradores y familiares. Sin embargo, tanto las exigencias para la producción y calificación académica como los requisitos a estímulos y promociones, no han cambiado. No se han implementado políticas transversales que consideren la estrecha relación entre vida personal y laboral que evidentemente vivimos en pandemia, ni la diversidad de realidades entre académicos. Se requiere considerar el género en la planificación y criterios de evaluación, así como ajustar las demandas académicas.

Las medidas transversales que sí se valoran -aunque solo sea una universidad de la muestra la que las practica-son las pausas académicas, las pausas activas, acompañamiento psicológico para los hijos de funcionarios, ejercicio físico regular, capacitaciones de distinto tipo para adecuarse a la modalidad online, entre otras. 
"... las pausas académicas son una instancia en donde, tanto a los docentes y a los estudiantes, les daban tres días al mes en donde estás $100 \%$ offline (...) la otra cosa que también reaccionó bastante bien es que generó pausas activas, entonces cuando uno estaba trabajando en el computador, de repente te aparece un correo y te dice 'conéctate acá' y te mandaban un video, un link, había un gallo atrás y decía 'ya, vamos haciendo ejercicio' cinco minutos, juf! de verdad ayudaba montones (...) nos mandaron a una serie de cursos de fortalecimiento docente, en liderazgo, manejo del estrés (...) cómo hacer docencia en modalidad online (...) el otro también que asistí fue uno de evaluación en la plataforma. Entonces en ese sentido tomaron varias directrices que fueron bastante útiles, muy muy útiles y que te permitían adaptarte fácilmente a estas condiciones de teletrabajo ¿̇ya? La otra cosa que también nos enviaron y que también estoy inscrita y, en la medida de lo posible cada vez que puedo lo hago, es el yoga que lo tengo los lunes y los miércoles y gimnasia activa que lo tengo los martes y los jueves a las seis de la tarde. (...) un sistema de acompañamiento estudiantil para los hijos de los colaboradores, yo ese también lo aproveché y también lo hizo para los colaboradores, en donde disponibilizaban estudiantes en prácticas de psicología para que atendieran a los hijos de estos. De hecho, a mis dos hijos los atendieron, súper bien y los acompañaban y conversaban y hablaban del día a día, y como que igual eso, que ellos estén hablando con otra persona, que es un psicólogo (...) fue bastante bueno para liberar tensiones. Los chiquillos se sentían bien, los míos por lo menos, se sentía bastante bien" (ID5, profesora asociada, ciencias biológicas, 46 años, casada, 2 hijos de 16 y 18 años).

\section{Conclusiones}

Los resultados de esta investigación muestran que las académicas enfrentan desafíos similares al resto de trabajadoras: una sobrecarga de trabajo de cuidado que pone en desventaja a las académicas teletrabajando en pandemia, quienes en su mayoría no cuentan con servicios externos de apoyo al cuidado (escuela, servicio doméstico). En concordancia con la literatura reciente sobre género y pandemia, las desigualdades de género en las universidades se han exacerbado y, además, se ha evidenciado con claridad las diferencias entre mujeres que cuidan de otros frente a aquellas que no tienen estas responsabilidades. De allí la importancia de establecer políticas universitarias con perspectiva de género.

Este artículo contribuye a generar conocimiento sobre los obstáculos en las trayectorias laborales de académicas universitarias que teletrabajan en tiempos de pandemia del COVID-19: la ceñida vinculación entre trabajo productivo y reproductivo genera diferencias significativas entre trabajadoras remotas de alta calificación.

El estudio muestra las diversas experiencias de académicas teletrabajando durante el confinamiento sanitario en Chile, país con una de las cuarentenas más extensas del mundo y un año escolar y universitario online. Se problematiza la inevitable relación entre vida laboral y personal/familiar durante la pandemia y sus efectos en las trayectorias laborales de académicas en Chile, lo que es extrapolable a otras académicas del orbe. Las distintas realidades de las profesoras universitarias teletrabajadoras han tenido implicancias diferenciadoras en su bienestar, en sus condiciones de trabajo y en sus proyecciones laborales. Pero ante esta diversidad, se muestra una escasa proactividad de las instituciones universitarias para abordar, a través de políticas de teletrabajo con perspectiva de género, las consecuencias de esta crisis sanitaria en sus colaboradores, particularmente, en mujeres con hijos menores. 
Los resultados discutidos en este artículo abordan el teletrabajo bajo pandemia -no en condiciones habituales de teletrabajo-, en un contexto caracterizado por una crisis sanitaria, social, económica y política. El miedo al contagio y las tensiones sociales cohabitan con la incertidumbre económica, lo que añade estresores importantes a la vida cotidiana y laboral de las personas. Por tanto, estos resultados no necesariamente son extensibles al teletrabajo en condiciones "normales". Con todo, al intensificar la coexistencia de los mundos privado y público durante la crisis, este estudio contribuye a esclarecer el significado, en prácticas cotidianas, de la atribución cultural del trabajo doméstico y de cuidado a las mujeres, un patrón que caracteriza la experiencia de trabajadoras alrededor del mundo (Minello, Martucci, y Manzo, 2020). Al fundirse los espacios público y privado durante el confinamiento, emergen con claridad los patrones de distribución del trabajo en virtud del género, que determinan posiciones diferenciadas y desiguales de mujeres con responsabilidades de cuidado y aquellos que no las tienen e intensifican la brecha de género en las universidades. Se vislumbra así el peso del género en el desarrollo laboral de mujeres de alta calificación y reflexividad, pero que de igual forma enfrentan sus trayectorias laborales sorteando individualmente las pugnas con lo doméstico.

Este artículo también tiene una contribución metodológica a la disciplina. La metodología visual utilizada para el desarrollo de las entrevistas resultó ser particularmente adecuada para la investigación social a través del uso de plataformas (entrevista foto-provocada remota). Las fotografías de las experiencias de teletrabajo, solicitadas a las entrevistadas, les permitió reflexionar, elaborar respecto a sus experiencias, así como sintetizar y simbolizar a través de imágenes sus sensaciones y emociones sobre el teletrabajo en pandemia. Las fotos mostraron más que las palabras, y en la mayoría de los casos, facilitó la conversación tras una pantalla y ayudó al vínculo y empatía entre investigadora y participante.

Esta investigación sobre las experiencias de trabajo remoto de académicas abre nuevas preguntas de interés para cientistas sociales enfocados en la comprensión del vínculo entre condiciones macro-sociales y las posibilidades de generar trayectorias laborales satisfactorias para las mujeres. La invasión de lo público en el mundo personal y la simultaneidad de labores de las académicas; las realidades desdibujadas que negocian; la presentación del yo frente a las cámaras, entre otros, son aspectos que contribuirán a retratar la complejidad de este momento y re-imaginar la diversidad en las experiencias de teletrabajo académico de mujeres.

Una mixtura de lo presencial y online son caminos posibles en el futuro. Sin embargo, factores personales y familiares son clave para que aquello se produzca sin efectos negativos para las trayectorias académicas. Paliar las diferentes posiciones sociales y personales entre académicos en el desarrollo de sus carreras no pueden sostenerse solamente en los individuos. Las universidades tienen un rol relevante en evitar que las desigualdades de género se profundicen aún más. Instamos a las instituciones de educación superior a implementar políticas de teletrabajo con perspectiva de género. 


\section{Bibliografía}

Araujo, K. (2017). Sujeto y neoliberalismo en Chile: rechazos y apegos. Nuevo Mundo, Mundos Nuevos. https://doi.org/10.4000/nuevomundo.70649

Bartos, A.E., y Ives, S. (2019). 'Learning the rules of the game': emotional labor and the gendered academic subject in the United States. Gender, Place \& Culture, 26 (6), 778-794. https://doi.org/10.1080/0966369X.2018.1553860

Bradshaw, S. (2015). Engendering Development and Disasters. Disasters, 39, 54-75. https://doi.org/10.1111/disa.12111

Bravo, D., Castillo, E., y Hughes, E. (2020). Estudio Longitudinal Empleo-COVID19: Datos de empleo en tiempo real. Centro UC de Encuestas y Estudios Longitudinales. Chile. Recuperado de https://www.uc.cl/site/efs/files/1 1364/presentacion-estudio-empleo-covid19-13082020.pdf

Cappello, M. (2005). Photo interviews: Eliciting data through conversations with children. Field methods, 17 (2), 170-182. https://doi.org/10.1 177/1525822X05274553

Colegio Médico de Chile. (2020). Mujeres en la pandemia: Más exposición a pacientes COVID 19, mayores efectos en salud mental y menor consulta médica por sospecha de contagio. Recuperado de http://bit.ly/ColMedico2020

Fardella, C., Sisto, V., y Jiménez, F. (2017). La transformación de la universidad y los dispositivos de cuantificación. Estudios de Psicología, 34 (3), 435-448. https:// doi.org/10.1590/1982-02752017000300011

Fazackerley, A. (12 mayo 2020). Women's research plummets during lockdown but articles from men increase. The Guardian. Recuperado de http://bit.ly/ TheguardianWomenResearch

Gabster, B.P., van Daalen, K., Dhatt, R., y Barry, M. (2020). Challenges for the female academic during the COVID-19 pandemic. The Lancet, 395(10242), 1968-1970. https://doi.org/10.1016/S0140-6736(20)31412-4

Gárate, M. (2012). La revolución capitalista de Chile (1973-2003). Santiago, Chile: Ediciones Universidad Alberto Hurtado.

Glaser, B., y Holton, J. (2004). Remodeling grounded theory. Forum Qualitative Sozialforschung / Forum: Qualitative Social Research, 5 (2). http://dx.doi. org/10.17169/fas-5.2.607

Glaser, B., y Strauss, A. (1998). Grounded theory: Strategien Qualitativer Forschung. Bern: Huber.

Han, C. (2012). Life in Debt: Times of Care and Violence in Neoliberal Chile. Berkeley, USA: University of California Press.

Harper, D. (2002). Talking about pictures: A case for photo-elicitation. Visual Studies, 17 (1), 13-26. https://doi.org/10.1080/14725860220137345

INE. Instituto Nacional de Estadísticas. (2020a). Boletín Estadístico: Empleo trimestral. Edición $n^{\circ} 260,30$ de junio 2020. Recuperado de http://bit.ly/ine20jun2020 . (2020b). Género e ingresos. Chile. Recuperado de http://bit.ly/inegeneroingresos - (2020c). Boletín Estadístico: Informalidad laboral. Edición n 10, 6 de mayo de 2020. Recuperado de http://bit.ly/ineinformalidad

. (2020d). Boletín Complementario No2. Remuneraciones y Costo de la Mano de Obra. Módulo COVID-19 IR-ICMO. Junio-septiembre 2020, 13 de noviembre de 2020. Recuperado de http://bit.ly/ineremuneracionesCovid

Krause, M. (1995). La investigación cualitativa: un campo de posibilidades y desafíos. Revista Temas de Educación, 7, 19-39.

López-Calva, L. (3 noviembre 2020). ¿̇No hay lugar más seguro que el hogar?: El aumento en la violencia doméstica y de género durante los confinamientos por COVID-19 en ALC. PNUD Recuperado de http://bit.ly/undpViolenciaCovid

Lutter, M., y Schröder, M. (2019). Is There a Motherhood Penalty in Academia? The Gendered Effect of Children on Academic Publications in German Sociology. European Sociological Review, 36(3), 442-459. https://doi.org/10.1093/esr/ jCZO63

Mandiola, M., Ríos, N., y Varas, A. (2019). "Hay un tema que no hemos conversado". La cassata como organización académica generizada en las universidades chilenas. Pensamiento Educativo, 56 1), 1-16. https://doi.org/10.7764/ PEL.56.1.2019.10 
Martínez Labrín, S. (2012). Ser o no ser: tensión entre familia, subjetividad femenina y trabajo académico en Chile: Un análisis de desde la psicología feminista. La ventana. Revista de estudios de género, 4 (35), 133-163. Recuperado de http://www.scielo.org.mx/scielo.php?pid=\$1 405-94362012000100006\&script=sci_abstract

McLaren, H.J., Wong, K.R., Nguyen, K.N., y Mahamadachchi, K.N.D. (2020). COVID-19 and Women's Triple Burden: Vignettes from Sri Lanka, Malaysia, Vietnam and Australia. Soc. Sci. 9 (5), 87. https://doi.org/10.3390/socsci9050087

Meo, A. I. (2010). Picturing students' habitus: The advantages and limitations of photo-elicitation interviewing in a qualitative study in the city of Buenos Aires. International Journal of Qualitative Methods, 9 (2), 149-171. https://doi. org/10.1177/160940691000900203

Meo, A., y Dabenigno, V. (2011). Imágenes que revelan sentidos: ventajas y desventajas de la entrevista de foto-elucidación en un estudio sobre jóvenes y escuela media en la Ciudad de Buenos Aires. Empiria. Revista de metodología de ciencias sociales, (22), 13-42. Recuperado de https://www.redalyc. org/pdf/2971/297124014001.pdf

Micropolíticas del Cuidado. (2020). Estudio Cuidar. Estudio sobre tiempos, formas y espacios de cuidado en casa durante la pandemia. Recuperado de https:// www.micropoliticasdelcuidado.cl/estudios

Minello, A., Martucci, S., y Manzo, L.K. (2020). The pandemic and the academic mothers: present hardships and future perspectives. European Societies. https://doi.org/10.1080/14616696.2020.1809690

Ministerio de la Mujer y la Equidad de Género de Chile (Minmujeryeg). (2020). Resultados ENERICOV-2020: Encuesta de Evaluación Rápida sobre el Impacto del COVID-19. Recuperado de https://minmujeryeg.gob.cl/?page_id=36433

Mondal, S. H. (2014). Women's vulnerabilities due to the impact of climate change: Case from Satkhira region of Bangladesh. Global Journal of Human Social Science, 14 (5), 46-52. https://globaljournals.org/GJHSS_Volume14/5-Womens-Vulnerabilities-due.pdf

Montes, E. y Simbürger, E. (forthcoming, 2021). La académica malabarista y la ausencia de políticas universitarias de conciliación: un estudio comparado de trabajo académico y familia en Chile y España. Education Policy Analysis Archives.

Mora, C. (2019). Interseccionalidad y fronteras sociales: género y clase social en el mercado laboral chileno. Estudios Públicos, (156), 47-67.

Mora, C., y Blanco, O. (2018). The Gender Deficit: Everyday Practices of Differentiation in the Chilean Labour Market. Bulletin of Latin American Research 37 (3), 291-305. https://doi.org/10.1111/blar.12672

Mora, C. (2013). La Imperceptibilidad del Género. En C. Mora (ed.), Desigualdad en Chile: La Continua Relevancia del Género (pp. 21-37). Santiago, Chile: Editorial Universidad Alberto Hurtado.

Moreno, J., y Shaw, D. (2018). Women's empowerment following disaster: A longitudinal study of social change. Natural Hazards, (92), 205-224. https://doi. org/10.1007/s1 1069-018-3204-4

MOVID-19. Monitoreo Nacional de Síntomas y Prácticas COVID-19 en Chile. (2020). ¿Cuál ha sido el impacto de la pandemia en los cuidados? Un análisis desde una perspectiva de género. Recuperado de https://movid19.cl/

ONU Mujeres. (2020). Cuidados en América Latina y el Caribe en tiempos de COVID-19. Hacia sistemas integrales para fortalecer la respuesta y la recuperación. Recuperado de https://www.cepal.org/es/publicaciones/45916-cuidados-america-latina-caribe-tiempos-COVID-19-sistemas-integrales-fortalecer

Ortiz, F. (2017). Vida familiar y trayectorias académicas: una aproximación biográfica en una universidad chilena. Polis (Santiago), 16 (47), 257-279. https://doi. org/10.4067/S0718-65682017000200257

Papademas, D., y International Visual Sociology Association. (2009). IVSA code of research ethics and guidelines. Visual Studies, 24 (3), 250-257. https://doi. org/10.1080/14725860903309187

Pinazo-Hernandis, S. (2020). Psychosocial impact of COVID-19 on older people: Problems and challenges. Revista Española de Geriatria y Gerontologia, 55(5), 249-252. https://doi.org/10.1016/j.regg.2020.05.006

Prosser, J. (1998). The Status of Image Based Research. En J. Prosser (Ed.) Image 
Based Research: A Sorcebook for qualitative Researchers (pp. 97-112). UK: Falmer Press.

Red Chilena contra la Violencia hacia las Mujeres. (2020). Dossier informativo: 2019-2020. Recuperado de http://www.nomasviolenciacontramujeres.cl/ wp-content/uploads/2020/08/dossier-red-corre.pdf

Ríos, N., Mandiola, M., y Varas, A. (2017). Haciendo género, haciendo academia: Un análisis feminista de la organización del trabajo académico en Chile. Psicoperspectivas, 16(2), 114-124. https://doi.org/10.5027/psicoperspectivas-Vol16-Issue2-fulltext-1041

Santos, G.G. (2015). Narratives about work and family life among Portuguese academics. Gender, Work \& Organization, 22 (1), 1-15. https://doi.org/10.1111/ gwao.12061

Sharma, N. (2020). The Global COVID-19 Pandemic and the Need to Change Who We Think "We" Are. Theory \& Event 23(5), S-19-S-29. https://www.muse.jhu. edu/article/775399

SIES. Servicio de Información de Educación Superior. (2017). Informe personal académico en educación superior 2017. Recuperado de http://www.mifuturo.cl/ index.php/informessies/academicos

Simbürger, E. (18 Julio 2020a). Escribir el desastre. Del jabón al cajón, del aula virtual intubada al fracaso feliz. [Blog Tiempos Nr. 7 de la Revista Latinoamericana del Colegio Internacional de Filosofía]. Recuperado de http://bit.ly/ Simbuerger2020

- (10 Junio 2020b). La universidad del desastre. Trabajo académico y género en tiempos de pandemia. [Blog Tiempos Nr. 4 de la Revista Latinoamericana del Colegio Internacional de Filosofía]. Recuperado de http://www.revistalatinoamericana-ciph.org/2020/06/10/903/

Sisto, V. (2020). Desbordadas/os: Rendición de cuentas e intensificación del trabajo en la universidad neoliberal. El caso de Chile. Archivos Analíticos de Políticas Educativas, 28 (7). https://doi.org/10.14507/epaa.28.4907

Undurraga, R., y López Hornickel, N. (2021). (Des)articuladas por el cuidado: trayectorias laborales de mujeres chilenas. Revista de Estudios Sociales, (75), 1-16. https://doi.org/10.7440/res75.2021.06

Undurraga, R. (2019a). Who Will Get the Job? Hiring Practices and Inequalities in the Chilean Labour Market. Bulletin of Latin American Research, 38 (5), 575590. https://doi.org/10.1111/blar.12888

. (2019b). Desigualdades en el trabajo: inequidades en la vejez. En CuaderniIlo Género y Políticas Públicas: Una mirada necesaria de la vejez (pp. 47-56). Santiago, Chile: Universidad de Chile. https://doi.org/10.34720/m52w-ae33

Undurraga, R., y Becker, J. (2019). Mujeres trabajadoras jóvenes y pensiones en Chile. Psicoperspectivas, 18 (3) http://dx.doi.org/10.5027/psicoperspectivas-vol18-issue3-fulltext-1658

Undurraga, R., y Simbürger, E. (2018). Género y políticas institucionales en universidades chilenas: un desierto con incipientes oasis estatales. En C. Mora, A. Kottow, V. Osses, M. Ceballos (Eds.), El género furtivo: la evidencia interdisciplinaria del género en el Chile actual. Santiago, Chile: LOM ediciones.

Undurraga, R. (2013). Mujer y trabajo en Chile: ¿Qué dicen las mujeres sobre su participación en el mercado laboral?. En C. Mora (Ed.), Desigualdad en Chile: La continua relevancia del género (pp. 113-141). Santiago, Chile: Ediciones Universidad Alberto Hurtado.

Undurraga, T. (2014). Divergencias: trayectorias del neoliberalismo en Argentina y Chile. Santiago, Chile: Ediciones Universidad Diego Portales.

Veliz, D., y Bernasconi, A. (2019). Los académicos en la educación superior chilena: una profesión en transición. En A. Carrasco y L. Flores (Eds.), De la Reforma a la Transformación. Capacidades, Innovaciones y Regulación de la Educación Chilena (pp. 323-347). Santiago, Chile: Ediciones UC.

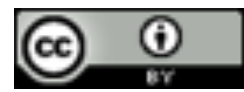

Este es un artículo de acceso abierto bajo licencia Creative Commons Reconocimiento 4.0 Internacional 